\title{
The impact of mild renal dysfunction on isolated cardiopulmonary coronary artery bypass grafting: a retrospective propensity score matching analysis
}

\author{
Xian Wang ${ }^{2+}$, Yifan Zhu ${ }^{1 \dagger}$, Wen Chen ${ }^{1}$, Liangpeng $\mathrm{Li}^{1}$, Xin Chen ${ }^{1}$ and Rui Wang ${ }^{1 *}$
}

\begin{abstract}
Background: Mild preoperative renal dysfunction (RD) is not rare in patients receiving isolated cardiopulmonary coronary artery bypass grafting (CCABG). However, there are not too many studies about the impact of mild preoperative RD on in-hospital and follow-up outcomes after isolated CCABG. This single-centre, retrospective propensity score matching study designed to study the impact of mild preoperative RD on in-hospital and longterm outcomes after first isolated CCABG.
\end{abstract}

Methods: After propensity score matching, 1144 patients with preoperative estimated glomerular filtration rate (eGFR) of more than $60 \mathrm{ml} / \mathrm{min} / 1.73 \mathrm{~m}^{2}$ receiving first isolated CCABG surgery from January 2012 to December 2015 entered the study, who were divided into 2 groups: A group (eGFR $\geq 90 \mathrm{ml} / \mathrm{min} / 1.73 \mathrm{~m} 2, n=572$ ) and B group (eGFR of 60-89 ml/min/1.73 m2, $\mathrm{n}=572$ ). The in-hospital and long-term outcomes were recorded and analyzed. The mean follow-up time was $54.4 \pm 10.7$ months. Acute kidney injury (AKI) was defined and classified according to the Acute Kidney Injury Network (AKIN) criteria.

Results: The 2 propensity score-matched groups had similar baseline and procedure except the baseline eGFR. There were 8 patients died in A group (mortality is 1.4\%) and 14 died in B group (mortality is 2.5\%) during the in hospital and 30 -day postoperatively $\left(x^{2}=1.159, p=0.282\right)$. There were totally 38 patients lost to follow-up, 18 in group A and 20 in group B. 21 patients died in group A and 37 died in group B during the follow-up, and longterm survival in group $A$ was higher than in group $B\left(96.2 \%\right.$ vs $\left.93.1 \%, X^{2}=4.336, p=0.037\right)$. Comparing with group A, group B was associated with an increased rates and severity of AKI postoperatively (total AKI: 62 vs 144. AKIN stagel: 54 vs 113; AKIN stagell: 6 vs 22; AKIN stagelll: 2 vs 9, $p<0.0001$ ). During follow-up, group B also had a higher rate of new onset of dialysis ( 0 vs $6, X^{2}=4.432, p=0.039$ ). Multivariable logistic regression showed that comparing with A group, the HR for long-term mortality and new onset of dialysis in B group was 1.67 and 1.52 respectively $(95 \% \mathrm{Cl} 1.09-2.90, p=0.035 ; 95 \% \mathrm{Cl} 1.14-2.49, p=0.027)$.

Conclusions: Comparing with normal preoperative renal function, patients with mild preoperative RD had a similar in-hosptial mortality, but with an increased in-hosptial rates and severity of AKl, and with a decreased long-term survival and increased long-term new onset of dialysis.

Keywords: Coronary artery bypass grafting, Cardiopulmonary, Glomerular filtration rate, Mild renal dysfunction, Inhospital outcomes, Long-term survival, Dialysis

\footnotetext{
*Correspondence: wr1582@163.com

${ }^{\dagger}$ Xian Wang and Yifan Zhu contributed equally to this work.

'Department of Cardiovascular Surgery, Nanjing First Hospital, Nanjing

Medical University, Nanjing, 68 Changle Rd, Nanjing 210006, People's

Republic of China

Full list of author information is available at the end of the article
}

(c) The Author(s). 2019 Open Access This article is distributed under the terms of the Creative Commons Attribution 4.0 International License (http://creativecommons.org/licenses/by/4.0/), which permits unrestricted use, distribution, and

reproduction in any medium, provided you give appropriate credit to the original author(s) and the source, provide a link to the Creative Commons license, and indicate if changes were made. The Creative Commons Public Domain Dedication waiver (http://creativecommons.org/publicdomain/zero/1.0/) applies to the data made available in this article, unless otherwise stated. 


\section{Background}

Nowadays, coronary artery bypass grafting surgery (CABG) is recognized as one of the most effective procedures for the treatment of coronary artery atherosclerosis disease. Patients with renal dysfunction (RD) are known to be at higher risk for mortality after CABG [1]. However, there is limited information on effects of different degrees of RD based on estimated glomerular filtration rate (eGFR), especially the studies focused on the mild preoperative RD are relatively rare [2].

The majority of previous studies usually utilized serum creatinine as the indicator of the severity of RD, but compared with creatinine levels, eGFR has been considered as the most reliable indicator of renal function according to the National Kidney Foundation guidelines [3, 4]. RD caused by cardiopulmonary bypass can be attributed to inflammatory response, nonpulsatile flow, hemodilution, renal hypoperfusion, low cardiac output syndrome, atheroembolism, increased levels of circulating catecholamines, and free hemoglobin $[5,6]$. However, studies conducted previously in this field have provided conflicting outcomes to support this hypothesis $[7,8]$.

In order to avoid the bias of cardiopulmonary bypass (CPB), we only enrolled patients with preoperative eGFR of more than $60 \mathrm{ml} / \mathrm{min} / 1.73 \mathrm{~m}^{2}$ undergoing first isolated cardiopulmonary coronary artery bypass grafting (CCABG) surgery. The purpose of this study was to understand the impact of mild preoperative RD compared with normal renal function on in-hospital and long-term outcomes in a single centre, retrospective propensity score matching study.

\section{Methods}

\section{Definition of renal function}

The glomerular filtration rate (GFR) was calculated by the abbreviated Modification of Diet in Renal Disease equation: $186 \times(\text { serum creatinine } / 88.4)^{-1.154} \times(\text { age })^{-0.203} \times$ (0.742 if female). Kidney function before CABG was graded from $\mathrm{I}$ to $\mathrm{V}$ according to the GFR as proposed by the Kidney Disease Outcome Quality Initiative [9]. Kidney function is defined as normal with a GFR more than $89 \mathrm{ml} / \mathrm{min} / 1.73 \mathrm{~m}^{2}$ (stage I), minimally reduced with a GFR between 60 and 89 (stage II), moderately reduced with a GFR between 30 and 59 (stage III), severely reduced with a GFR between 15 and 29 (stage IV), and end-stage kidney failure with a GFR below 15 or renal replacement (stage V). This study only enrolled patients with mild preoperative RD (GFR between 60 and $89 \mathrm{ml}$ / $\mathrm{min} / 1.73 \mathrm{~m}^{2}$ ) and patients with normal preoperative renal function (GFR more than $90 \mathrm{ml} / \mathrm{min} / 1.73 \mathrm{~m}^{2}$ ).

\section{Study population}

A standard set of perioperative data was collected prospectively for all patients undergoing first isolated CCABG with preoperative eGFR of more than $60 \mathrm{ml} / \mathrm{min} / 1.73 \mathrm{~m}^{2}$ at Nanjing First Hospital between January 2010 to December 2015. Clinical data were retrospectively collected from medical records and the data-base of our department of cardiac surgery.

All CCABG surgeries were performed by the one surgeon. Patients undergoing a concomitant cardiac surgical procedure, reoperation, urgent or emergent operations, or with incomplete informations were excluded. CCABG was performed via median sternotomy using a membrane oxygenator equipped with an arterial filter, cold blood antegrade cardioplegia under moderate systemic hypothermia (30 to $34^{\circ} \mathrm{C}$ ). The perfusion pressure during $\mathrm{CPB}$ was maintained within $60-70 \mathrm{mmHg}$.

Totally there were 1592 cases up to the standard, normal preoperative renal function was found in 1020 patients (64.1\%, A group) and mild preoperative RD in 572 patients (35.9\%, B group).

To control the selection bias in the comparison among A group and B group, a propensity score (PS) analysis was performed. One PS was calculated for each patient by means of logistic-regression analysis using 18 preoperative and surgical variables including: age, gender, body mass index (BMI), smoking, hypertension, diabetes mellitus (DM), hyperlipemia, chronic obstructive pulmonary disease (COPD), prior cerebro-vascular accident, history of cerebral and myocardial infarction (MI), history of percutaneous coronary intervention (PCI), left ventricular ejection fraction (LVEF), number of vessel disease, Euro-SCOREII, number of distal anastomosis, the application of left internal mammary artery (LIMA) and radial artery and CPB time. Every patient with mild preoperative RD was matched with a patient with normal renal function with the closest PS (within0.030). Finally, 572 pairs were successfully built in a 1:1 manner through matching PS(A group, $n=572$; B group, $n=572$ ).

\section{Statistical analysis}

Data are represented as the mean \pm standard deviation (SD) unless otherwise indicated. Categorical variables are represented as frequency distributions and single percentages. Normally distributed continuous variables were compared using a Student t-test, non-normally distributed continuous variables using the Mann-Whitney $U$ test, and categorical variables were compared by $x^{2}$ test. Potential risk factors were calculated by Cox regression analysis. Potential independent predictors of outcome were identified by univariate Cox regression analysis. All statistical tests were two-sided. A $p$-value of less than 0.05 was considered significant. All statistical analysis were done with IBM SPSS Statistics 20.0 or STATA Data analysis and statistical software. 


\section{Results}

\section{Matching of patients}

Matching data from A group $(n=572)$ and B group $(n=$ 572) were analyzed. There were no significant differences with regard to age, gender, BMI, smoking, hypertension, DM, hyperlipedemia, COPD, history of cerebral infarction, history of MI, history of PCI, LVEF, number of vessel disease, Euro-SCOREII, number of distal anastomosis, the percentage of arterial grafts and $\mathrm{CPB}$ time (Table 1). Significant differences were found on the baseline eGFR, which was higher in A group than B group $(101.3 \pm 11.4$ vs $75.6 \pm 9.7, p<0.0001)$.

Table 1 Baseline and procedural characteristics after matching

\begin{tabular}{|c|c|c|c|}
\hline \multirow[t]{2}{*}{ variable } & \multirow{2}{*}{$\begin{array}{l}\text { A group } \\
(n=572) \text { No. }(\%)\end{array}$} & B group & \multirow[t]{2}{*}{$p$ value } \\
\hline & & $\begin{array}{l}(n=572) \\
\text { No. }(\%)\end{array}$ & \\
\hline Female gender & $97(17.0)$ & $104(18.2)$ & 0.641 \\
\hline Age, y & $63.2 \pm 7.3$ & $63.6 \pm 8.1$ & 0.38 \\
\hline Body mass index, kg/m2 & $26.4 \pm 4.5$ & $26.1 \pm 4.6$ & 0.265 \\
\hline \multicolumn{4}{|l|}{ DM } \\
\hline Insulin-dependent & 89 (15.6) & $95(16.6)$ & 0.687 \\
\hline Non-Insulin-dependent & $63(11.0)$ & $71(12.4)$ & 0.52 \\
\hline \multicolumn{4}{|l|}{ Previous } \\
\hline Cerebal infarction & $28(4.9)$ & $23(4.0)$ & 0.567 \\
\hline Myocardial infarction & $85(14.9)$ & $91(15.9)$ & 0.682 \\
\hline $\mathrm{PCl}$ & 79 (13.8) & $83(14.5)$ & 0.799 \\
\hline Hypertension & $286(50.0)$ & $317(55.4)$ & 0.076 \\
\hline COPD & $38(6.6)$ & $44(8.5)$ & 0.567 \\
\hline Hyperlipemia & $143(0.25)$ & $132(23.1)$ & 0.489 \\
\hline LVEF & & & 0.388 \\
\hline$>0.50$ & $479(83.7)$ & $468(81.8)$ & \\
\hline $0.30-0.50$ & $87(15.2)$ & $97(17.0)$ & \\
\hline$<0.30$ & $6(1.1)$ & $7(1.2)$ & \\
\hline Extent of CAD & & & 0.795 \\
\hline 1 vessel & $14(2.5)$ & $13(2.3)$ & \\
\hline 2 vessel & $69(12.1)$ & $67(11.7)$ & \\
\hline 3 vessel & $489(85.4)$ & $492(86.0)$ & \\
\hline LM & $165(28.8)$ & $151(26.4)$ & 0.39 \\
\hline eGFR (ml/min/1.73 m2) & $101.3 \pm 11.4$ & $75.6 \pm 9.7$ & $<0.0001$ \\
\hline EuroScorell & $1.9 \pm 0.9$ & $2.0 \pm 1.2$ & 0.111 \\
\hline Distal anastomosis & $3.1 \pm 0.6$ & $3.1 \pm 0.4$ & 1 \\
\hline LIMA & $544(95.1)$ & $531(92.8)$ & 0.136 \\
\hline Radial Artery & $68(11.9)$ & 89 (15.6) & 0.086 \\
\hline CPB time (min) & $73.5 \pm 20.2$ & $71.3 \pm 23.8$ & 0.092 \\
\hline
\end{tabular}

$D M$ diabetes mellitus, $P C I$ percutaneous coronary intervention, $C O P D$ chronic obstructive pulmonary disease, $L V E F$ left ventricular ejection fraction, $C A D$ coronary artery disease, eGFR estimated glomerular filtration rate, LIMA left internal mammary artery, $C P B$ cardiopulmonary bypass

\section{Postoperative results}

A total of 22 patients died after the operation (8 in A group and 14 in $\mathrm{B}$ group, $p=0.282$ ). In-hospital mortality and morbidity are represented in Table 2 . There were no significant differences with regard to in-hospital mortality, myocardial infarction, atrial fibrillation, stroke, respiratory failure, pneumonia, redo for bleeding, red blood cell (RBC) transfusion, deep sternal wound infection (DSWI), low cardiac output syndrome, intra-aortic balloon pump (IABP) support. Comparing with group A, group B was associated with an increased rates and severity of AKI (total AKI: 62 vs 144. AKIN stageI: 54 vs 113; AKIN stageII: 6 vs 22; AKIN stageIII: 2 vs 9, $p<0.0001$.) (Fig. 1 ).

\section{Long-term outcomes}

There were 58 patients died during the follow-up (21 patients in A group and 37 in B group), and 38 patients were lost to follow-up totally (18 patients in A group and 20 in B group, Table 2). The mean follow-up time was $54.4 \pm 10.7$ months. The top three causes of death were infection, heart failure, and myocardial infarction. Patients in group A were associated with a higher longterm survival (Fig. 2), and a lower new onset of dialysis rate than patients in group B (long-term mortality, 21 vs 37 , long-term survival, 525 vs $501, \chi^{2}=4.336, p=0.037$; dialysis, 0 vs $\left.6, x^{2}=4.432, p=0.039\right)$. Multivariable logistic regression showed that mild preoperative RD grouping was a significant variable related to the long-term survival rate and new onset of dialysis, the HR for longterm mortality and new onset of dialysis in patients with mild preoperative RD was 1.67 and 1.52 respectively compared with normal preoperative renal function (95\% CI 1.09-2.90, $p=0.035$; 95\%CI $1.14-2.49, p=0.027$ ). (As shown in Table 3 ).

\section{Discussion}

The principal findings of this single-centre, retrospective propensity score matching study can be summarized as follows. Comparing with normal preoperative renal function, mild preoperative RD: (1) did not influence the in-hosptial mortality and most of the postoperative in-hosptial morbidities. (2) increased postoperative in-hosptial rates and severity of AKI. (3) decreased long-term survival and increased long-term new onset of dialysis.

Propensity matched pairs analysis provided the opportunity to rule out confusion by providing balanced baseline and procedural characteristics except the baseline eGFR. In this study, patients with mild preoperative RD or with normal preoperative renal function had similar rates of in-hospital surgical mortality. The univariate factor analysis manifested that the 2 propensity scorematched groups had similar in-hospital outcomes, including surgical mortality, myocardial infarction, stroke, respiratory failure, pneumonia, redo for bleeding, RBC 
Table 2 Postoperative outcomes in the matched cohort

\begin{tabular}{|c|c|c|c|}
\hline \multirow[t]{2}{*}{ variable } & \multirow{2}{*}{$\begin{array}{l}\text { A group } \\
(n=572) \text { No. }(\%)\end{array}$} & \multirow{2}{*}{$\begin{array}{l}\text { B group } \\
(n=572) \text { No. (\%) }\end{array}$} & \multirow[t]{2}{*}{$p$ value } \\
\hline & & & \\
\hline Mortality & $8(1.4)$ & $14(2.4)$ & 0.282 \\
\hline $\mathrm{Ml}$ & $17(3.0)$ & $17(3.0)$ & 1 \\
\hline Stroke & $6(1.0)$ & $8(1.4)$ & 0.788 \\
\hline Respiratory failure & $16(2.8)$ & $22(3.8)$ & 0.409 \\
\hline Pneumonia & $23(4.0)$ & $29(5.1)$ & 0.478 \\
\hline AKI & 62 & 144 & $<0.0001$ \\
\hline Stage I & $54(9.6)$ & $113(20.3)$ & \\
\hline Stage ॥ & $6(1.1)$ & $22(3.9)$ & \\
\hline Stage III & $2(0.4)$ & $9(1.6)$ & \\
\hline Redo for bleeding & $9(1.6)$ & $12(2.1)$ & 0.66 \\
\hline RBC transfusion & $201(35.1)$ & $219(38.3)$ & 0.622 \\
\hline DSWI & $11(1.9)$ & $17(3.0)$ & 0.339 \\
\hline Low cardiac output syndrome & $44(7.7)$ & $54(9.4)$ & 0.34 \\
\hline IABP application & $33(5.8)$ & $46(8.0)$ & 0.162 \\
\hline Lost to follow-up & $18(3.2)$ & $20(3.7)$ & 0.869 \\
\hline Long-term mortality & $21(3.8)$ & $37(6.9)$ & 0.037 \\
\hline CRF requiring dialysis & 0 & $6(1.1)$ & 0.039 \\
\hline
\end{tabular}

transfusion, DSWI, low cardiac output syndrome, IABP application, except the rates and severity of AKI. The same result was obtained by Weitie Wang et al., they reported older patients with mild preoperative RD had a higher mortality rate than normal patients in long-term survival, whereas no evidence of worse in-hospital mortality rate was found [10]. Jyrala et al. who analyzed a cohort of 885 patients with or without mild preoperative $\mathrm{RD}$ received on-pump cardiac surgery, with respect to short- and long-term outcomes [11]. They found mild preoperative $\mathrm{RD}$ was a marker for patients with increased cardiac risk factors and the risk for poor outcomes. Their conclusion was in line with our study about postoperative late survival but was different from in-hospital mortality. Reasons of this difference lay in the study population, because our cohort was primary isolated CCABG, and we chose the eGFR as the indicator for the evaluation of renal function.

$\mathrm{CPB}$ still contributes to RD due to multiple perturbations in renal physiology and function as mentioned before. We speculated the reasons why there was no difference of mortality between the 2 groups were as follows: (1) average

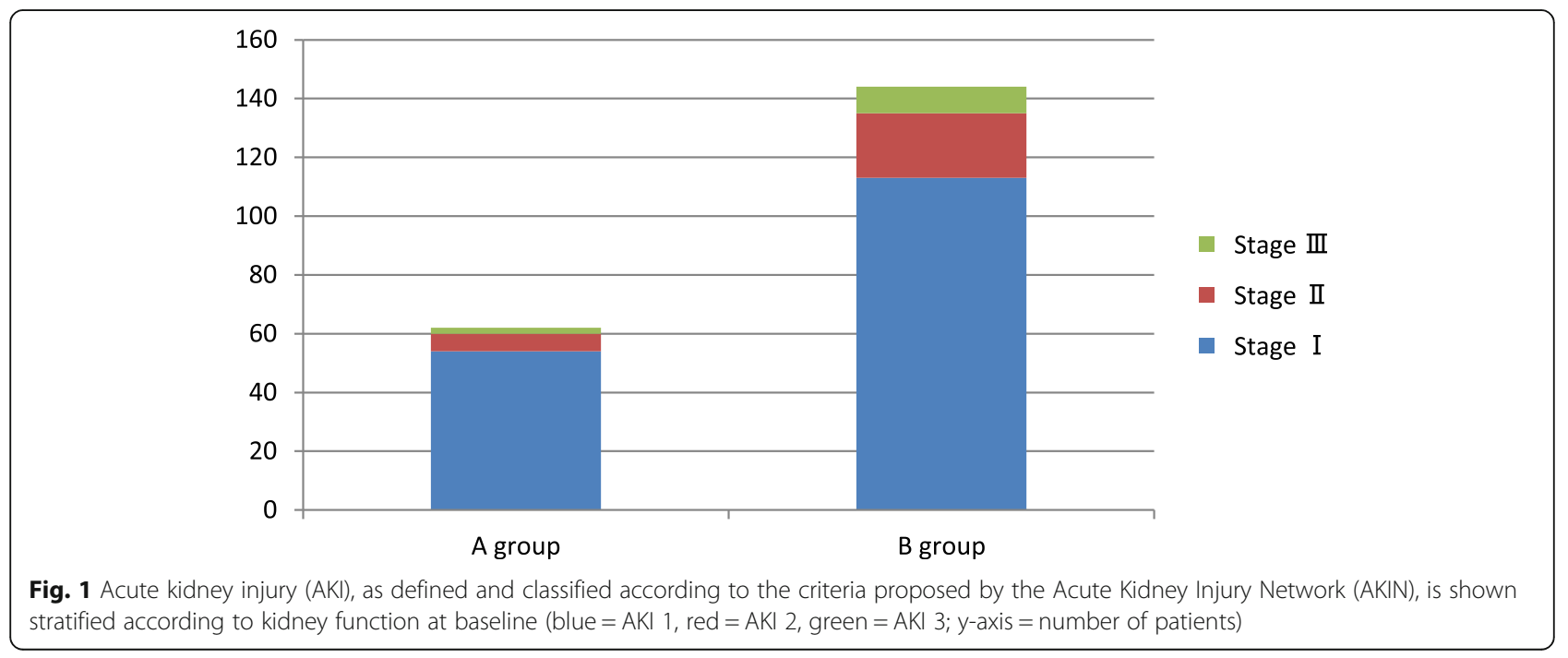




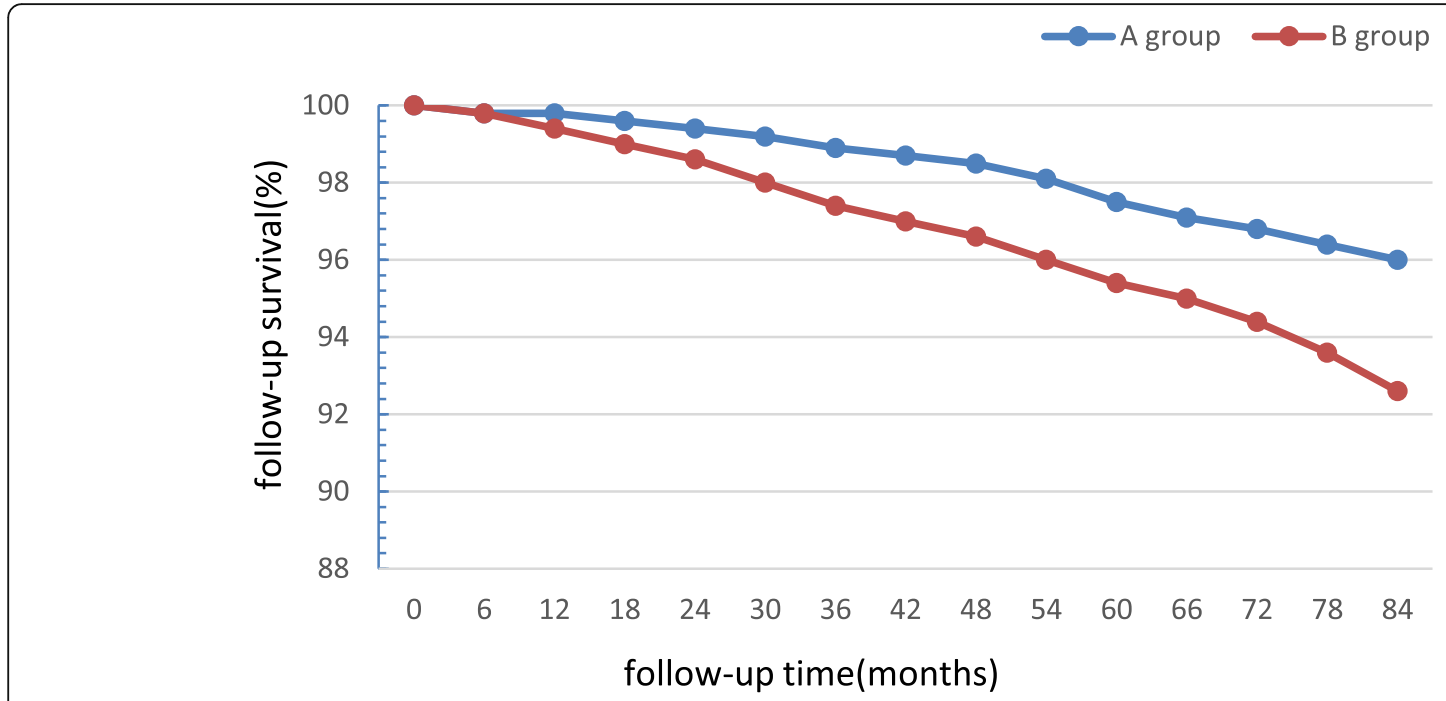

Fig. 2 Actuarial curves of long-term follow-up survival after CCABG

CPB time of primary isolated CABG was relatively short, most of patients with mild RD had enough functional reserve and had the ability to withstand acute insults. (2) group B had an increased postoperative in-hosptial rates and severity of AKI, but AKIN stage I accounted for most cases. (3) relative high perfusion pressure was kept to guarantee the renal perfusion [12]. (4) There are no active treatments for AKI, and therefore, perioperative preventative strategies seem particularly promising. Keep adequate hydration and avoid the use of diuretics, except for specified medical indications; minimize the use of medications with adverse effects on renal function, such as contrast agents, $\alpha$-adrenergic agents, colloids and exogenous blood products; keep an optimal hemodynamic status and correct the acid-base or metabolic imbalance.

It is reported that age, DM, preoperative RD, blood transfusion, low cardiac output syndrome, low LVEF are independent risk factors of AKI $[13,14]$. There was no significant difference of these independent risk factors except the baseline eGFR between the 2 propensity score-matched groups. In this study, compared with patients with normal preoperative renal function, patients with mild preoperative RD were associated with increased postoperative in-hosptial rates and severity of AKI. The severity of AKI was defined by the AKIN [15], AKIN stage I accounted for most patients in both groups in this study. AKI defines as a clinical syndrome characterized by a sudden decline of the excretory kidney function, with accumulation of urea and creatinine and decreased urinary output $[16,17]$. Depending on the specific definition and methodological concerns, AKI occurs in up to one third of patients undergoing CABG, and approximately $2 \%$ require temporary dialysis [18]. The AKIN criteria may be quite sensitive for detecting subtle changes in kidney function, especially the creatinine increase of $0.3 \mathrm{mg} / \mathrm{dL}$ within 2 days. Some previous studies demonstrated that development of AKI was associated with high short-term and long-term morbidity and mortality [19]. The demonstration was consistent with our study about the long-term mortality but was different from postoperative short-term mortality. Reason of this difference was supposed that we only recruited first isolated CCABG with normal or mild RD, and AKIN stage I accounted for most patients postoperatively, and higher incidence of

Table 3 Predictors of long-term mortality/new onset of dialysis in the matched cohorts

\begin{tabular}{llll}
\hline Variable & HR & $95 \% \mathrm{Cl}$ & $p$ value \\
\hline Grouping (mild group vs. normal group) & $1.67 / 1.52$ & $1.09-2.90 / 1.14-2.49$ & $0.035 / 0.027$ \\
Age (per y) & $1.21 / 1.19$ & $1.03-1.63 / 1.17-1.89$ & $<0.0001 / 0.004$ \\
Gender (Female vs. male) & $1.29 / 1.13$ & $1.08-1.84 / 1.03-2.01$ & $0.037 / 0.19$ \\
High blood pressure & $1.47 / 1.05$ & $1.12-1.97 / 1.05-1.88$ & $0.008 / 0.27$ \\
DM & $1.59 / 1.33$ & $1.08-1.96 / 1.01-1.76$ & $0.012 / 0.035$ \\
LVEF $<0.50$ & $1.68 / 2.24$ & $1.04-2.21 / 1.03-2.25$ & $0.023 / 0.006$ \\
IABP application & $2.22 / 3.17$ & $1.11-2.87 / 1.05-2.10$ & $<0.0001 / 0.002$
\end{tabular}

$H R$ hazard ratio, $\mathrm{Cl}$ confidence interval, $D M$ diabetes mellitus, $L V E F$ left ventricular ejection fraction, IABP intra-aortic balloon pump 
complete revascularization achieved by CCABG may also be a possible explanation. Another hypothesis was that the increased hemodynamic instability that occured with offpump CABG negate the benefits of avoiding CPB [20].

As expected, the follow-up demonstrated that patients with mild preoperative RD showed a trend to lower long-term survival compared with normal preoperative renal function patients $(96.2 \%$ vs $93.1 \%, p=0.037)$. Cox regression manifested that grouping (mild vs. normal preoperative renal function) was a significant variable related to the long-term survival, and the HR was 1.67 (95\%CI 1.09-2.90, $p=0.035$ ). Furthermore, in our study patients with mild RD were associated with a higher rate of new onset of dialysis compared with normal renal function patients during the follow-up ( 0 vs $6, x^{2}=4.432$, $p=0.039$ ). Cox regression also showed the HR for new onset of dialysis was 1.52 (mild vs normal preoperative renal function, 95\%CI 1.14-2.49, $p=0.027$ ). The exact causes of these differences are unknown and further research is needed. Preexisting kidney disease has been repeatedly identified as a strong predictor of AKI after cardiac operations [21], moreover, AKI has been associated with progression to chronic kidney disease (CKD) and dialysis in many reports [22]. CKD and dialysis might exert negative efferts on the long-term survival inevitably. Günday and colleagues [23] conducted a study focused on the CABG patients with normal renal function or mild RD, they concluded that mild preoperative $\mathrm{RD}$ reduced coronary flow reserve after CABG surgery due to deterioration of the micro-vascular bed. Unfortunately, there are no pharmacologic agents known to reduce the risk of AKI or treat established AKI [24]. Therefore, CABG patients with mild RD need to strengthen the follow-up of nephropathy, more strictly management of the risk factors of coronary artery disease postoperatively.

\section{Limitations}

Firstly, a retrospective, non-randomized single-centre analysis over a long period of time and with different surgeon's procedures on patients undergoing CABG is subjected to the effects of selection bias. Although propensity score matching is implemented, a prospective, multi-centre study involving larger sample size is needed. Secondly, the GFR was derived by using the MDRD formula, which was not designed for determining GFR. Finally, the initial RIFLE (risk of RD; injury to the kidney; failure of kidney function; loss of kidney function; and end-stage kidney disease) criteria do not include the creatinine increase within $48 \mathrm{~h}$ for defining the mildest form of AKI, whereas the RIFLE categories injury and loss are similar to AKIN stage 2 and 3, respectively [25]. AKI defined according to the RIFLE criteria may therefore avoid an iatrogenic hemodilution but may miss more subtle changes of kidney function $[19,25]$.

\section{Conclusions}

In summary, this analysis revealed that mild preoperative $\mathrm{RD}$ compared with normal preoperative renal function did not increase the in-hosptial mortality, but increased in-hosptial rates and severity of AKI, decreased longterm survival and increased long-term new onset of dialysis.

\section{Abbreviations \\ AKI: Acute kidney injury; AKIN: Acute kidney injury network; BMI: Body mass index; CABG: Coronary artery bypass grafting surgery; \\ CCABG: Cardiopulmonary coronary artery bypass grafting; CKD: Chronic kidney disease.; COPD: Chronic obstructive pulmonary disease; \\ CPB: Cardiopulmonary bypass; DM: Diabetes mellitus; DSWI: Deep sternal wound infection; eGFR: estimated glomerular filtration rate; GFR: Glomerular filtration rate; IABP: Intra-aortic balloon pump; LIMA: Left internal mammary artery; LVEF: Left ventricular ejection fraction; MI: Myocardial infarction; PCl: Percutaneous coronary intervention; PS: Propensity score; RBC: Red blood} cell

\section{Acknowledgements}

None

\section{Authors' contributions}

RW and XC conceived of the study, and participated in its design and coordination and helped to draft the manuscript. XW and YFZ participated in the design of the study and drafted the manuscript. WC and LPL carried out the data collection and statistical analysis. All authors read and approved the final manuscript, and agreed for publication.

\section{Funding}

This work was supported by National Natural Science Foundation of China (No.81870193); Medical Science and Technology Development Project of Nanjing (YKK14080).

Availability of data and materials

All data and material are available by contacting wr1582@163.com

Ethics approval and consent to participate

This study was approved by The Ethics Committee of Nanjing First Hospital. All patients agreed that their stored material was enclosed and that their

clinical data were anonymously used for statistical analysis.

Consent for publication

Written informed consent was obtained from the patient before publication.

\section{Competing interests}

The authors declare that they have no competing interests.

\section{Author details}

${ }^{1}$ Department of Cardiovascular Surgery, Nanjing First Hospital, Nanjing Medical University, Nanjing, 68 Changle Rd, Nanjing 210006, People's Republic of China. ${ }^{2}$ Department of Laboratory Medicine, Nanjing Drum Tower Hospital, Nanjing University Medical School, Nanjing, 321 Zhongshan Rd, Nanjing 210008, People's Republic of China.

Received: 4 August 2019 Accepted: 20 September 2019 Published online: 07 November 2019

\section{References}

1. García Fuster R, Paredes F, García Peláez A, et al. Impact of increasing degrees of renal impairment on outcomes of coronary artery bypass grafting: the off-pump advantage. Eur J Cardiothorac Surg. 2013;44(4): 732-42. 
2. Litmathe J, Kurt M, Feindt $P$, et al. The impact of pre- and postoperative renal dysfunction on outcome of patients undergoing coronary artery bypass grafting (CABG). Thorac Cardiovasc Surg. 2009;57(8):460-3.

3. Lunney M, Alrukhaimi M, Ashuntantang GE, et al. Guidelines, policies, and barriers to kidney care: findings from a global survey. Kidney Int Suppl (2011). 2018;8(2):30-40.

4. Levey AS, Coresh J, Balk E, et al. National Kidney Foundation practice guidelines for chronic kidney disease: evaluation, classification and stratification. Ann Intern Med. 2003;139(2):137-47.

5. Lannemyr $L$, Bragadottir $G$, Krumbholz V, et al. Effects of Cardiopulmonary Bypass on Renal Perfusion, Filtration, and Oxygenation in Patients Undergoing Cardiac Surgery. Anesthesiology. 2017;126(2):205-13.

6. Pickering JW, James MT, Palmer SC. Acute kidney injury and prognosis after cardiopulmonary bypass: a meta-analysis of cohort studies. Am J Kidney Dis. 2015;65(2):283-93.

7. Mao H, Katz N, Ariyanon W, et al. Cardiac surgery-associated acute kidney injury. Cardiorenal Med. 2013;3(3):178-99.

8. Wang Y, Bellomo R. Cardiac surgery-associated acute kidney injury: risk factors, pathophysiology and treatment. Nat Rev Nephrol. 2017;13(11):697-711.

9. KJDOQI Clinical Practice Guidelines for Chronic Kidney Disease: evaluation, classification, and stratification. Part 4: definition and classification of stages of chronic kidney disease. Am J Kidney Dis. 2002:39(2 Suppl 1):S1-266.

10. Wang $W$, Wang $Y, X u R$, et al. Outcomes following coronary artery bypass graft surgery in patients with mild preoperative renal insufciency. Braz J Cardiovasc Surg. 2018;33(2):155-61.

11. Jyrala A, Weiss RE, Jeffries RA, et al. Effect of mild renal dysfunction (s-crea1. 2-2.2 mg/dl) on presentation characteristics and short- and long-term outcomes of on-pump cardiac surgery patients. Interact Cardiovasc Thorac Surg. 2010;10(5):777-82.

12. Sgouralis I, Evans RG, Gardiner BS, et al. Renal hemodynamics, function, and oxygenation during cardiac surgery performed on cardiopulmonary bypass: a modeling study. Physiol Rep. 2015;3(1):1-14.

13. Landoni $\mathrm{G}$, Bove $\mathrm{T}$, Crivellari $\mathrm{M}$, et al. Acute renal failure after isolated $\mathrm{CABG}$ surgery: six years of experience. Minerva Anestesiol. 2007;73:559-65.

14. Helgadottir S, Sigurdsson Ml, Palsson R, et al. Renal recovery and long-term survival following acute kidney injury after coronary artery surgery: a nationwide study. Acta Anaesthesiol Scand. 2016;60(9):1230-40.

15. Kara I, Yildirim F, Kayacan E, et al. Importance of RIFLE (Risk, Injury, Failure, Loss, and End-Stage Renal Failure) and AKIN (Acute Kidney Injury Network) in Hemodialysis Initiation and Intensive Care Unit Mortality. Iran J Med Sci. 2017;42(4):397-403.

16. Bellomo R, Kellum JA, Ronco C. Acute kidney injury. Lancet. 2012;380(9843): 756-66.

17. Ostermann M, Liu K. Pathophysiology of AKl. Best Pract Res Clin Anaesthesiol. 2017;31(3):305-14.

18. Rosner MH, Okusa MD. Acute kidney injury associated with cardiac surgery. Clin J Am Soc Nephrol. 2006;1:19-32.

19. Reents W, Hilker M, Börgermann J, et al. Acute kidney injury after on-pump or off-pump coronary artery bypass grafting in elderly patients. Ann Thorac Surg. 2014;98(1):9-14.

20. Schwann NM, Horrow JC, Strong MD 3rd, et al. Does off-pump coronary artery bypass reduce the incidence of clinically evident renal dysfunction after multivessel myocardial revascularization? Anesth Analg. 2004;99:959-64.

21. Karkouti K, Wijeysundera DN, Yau TM, et al. Acute kidney injury after cardiac surgery: focus on modifiable risk factors. Circulation. 2009;119:495-502.

22. Chawla LS, Eggers PW, Star RA, et al. Acute kidney injury and chronic kidney disease as interconnected syndromes. N Engl J Med. 2014;371:58-66.

23. Günday M, Çiftçi Ö, Çalışkan M, et al. Does mild renal failure affect coronary flow reserve after coronary artery bypass graft surgery? Heart Surg Forum. 2014:17:E18-24.

24. Thiele RH, Isbell JM, Rosner MH. AKI associated with cardiac surgery. Clin J Am Soc Nephrol. 2015:10:500-14.

25. Bellomo R, Ronco C, Kellum JA, Metha RL, Palevsky P, the ADQI workgroup Acute renal failure-definition, outcome measures, animal models, fluid therapy and information technology needs: the second international consensus conference of the acute Dialysis quality initiative (ADQI) group. Crit Care. 2004;8:R204-12.

\section{Publisher's Note}

Springer Nature remains neutral with regard to jurisdictional claims in published maps and institutional affiliations.

Ready to submit your research? Choose BMC and benefit from:

- fast, convenient online submission

- thorough peer review by experienced researchers in your field

- rapid publication on acceptance

- support for research data, including large and complex data types

- gold Open Access which fosters wider collaboration and increased citations

- maximum visibility for your research: over $100 \mathrm{M}$ website views per year

At BMC, research is always in progress.

Learn more biomedcentral.com/submissions 